\title{
Supplementary Materials: Development of a yeast-based assay for bioavailable phosphorus
}

Heather A.M. Shepherd ${ }^{1}$, Matt T. Trentman ${ }^{2,4,6}$, Jennifer L. Tank ${ }^{2,4}$, Jennifer Praner ${ }^{1}$, Anissa Cervantes $^{1}$, Priya Chaudhary ${ }^{1,3}$, Jonah Gezelter ${ }^{1,5}$, Allyson J. Marrs ${ }^{2}$, Kathryn A. Myers ${ }^{1,3}$, Jonathan R. Welsh ${ }^{1}$, Yueh-Fu O. Wu ${ }^{1}$, Holly V. Goodson ${ }^{1,2,4^{*}}$

1. University of Notre Dame, Department of Chemistry and Biochemistry, Notre Dame, IN 46556, USA

2. University of Notre Dame, Department of Biological Sciences, Notre Dame, IN 46556, USA

3. University of Notre Dame, Department of Chemistry and Biochemistry REU, Notre Dame, IN 46556, USA

4. University of Notre Dame, Environmental Change Initiative, Notre Dame, IN 46556, USA

5. Adams High School, South Bend, IN 46615, USA

*Author for Correspondence:

Holly Goodson

Department of Chemistry and Biochemistry

University of Notre Dame, Notre Dame, IN 46556

hgoodson@nd.edu

Table of Contents

Pages

1. Supplementary Tables and Figures

Table S1

2

Table S2

2

Figure S1

3

Figure S2

4

2. Supplementary Methods

2.1. Sources of Chemicals and Materials 5

2.2. Preparation of Growth Media 5-6

2.3. Preparation of Phosphorus-Depleted Yeast Cultures 7

2.4. Cost Analysis 8

2.5. General notes related to running the assays 8

2.6. Centrifuge Tube Assay Protocol 9-11

2.7. Microtiter Plate Assay Protocol 12-14

3. Supplement References 15 


\section{Supplementary Tables and Figures}

Table S1. Measurements of bioavailable phosphorus in varied dilutions of a commercial fertilizer sample as determined by linear and fractional saturation fits to the centrifuge tube and microtiter plate assays. The conversion of these data to percent $\mathrm{P}$ are provided below in Table S2; these data are derived from Figure 2.

\begin{tabular}{c|cc|cc|c} 
& \multicolumn{2}{|c|}{ Centrifuge Tube Assay } & \multicolumn{2}{c|}{ Microtiter Assay } & \\
\hline $\begin{array}{c}\text { Input Phosphorus based } \\
\text { on Manufacturers Label }\end{array}$ & $\begin{array}{c}\text { P from Linear } \\
\text { Fit }\end{array}$ & $\begin{array}{c}\text { P from } \\
\text { Fractional } \\
\text { Saturation } \\
\text { Fit }\end{array}$ & $\begin{array}{c}\text { P from } \\
\text { Linear Fit }\end{array}$ & $\begin{array}{c}\text { P from } \\
\text { Fractional } \\
\text { Saturation Fit }\end{array}$ & $\begin{array}{c}\text { Input Phosphorus based on } \\
\text { Brookside TP Data }\end{array}$ \\
\hline $4.4 \mu \mathrm{M}$ & $2.4 \mu \mathrm{M}$ & $3.9 \mu \mathrm{M}$ & $2.9 \mu \mathrm{M}$ & $4.2 \mu \mathrm{M}$ & $4.1 \mu \mathrm{M}$ \\
$8.8 \mu \mathrm{M}$ & $7.0 \mu \mathrm{M}$ & $6.6 \mu \mathrm{M}$ & $8.1 \mu \mathrm{M}$ & $7.4 \mu \mathrm{M}$ & $8.3 \mu \mathrm{M}$ \\
$17.6 \mu \mathrm{M}$ & $15.7 \mu \mathrm{M}$ & $13.0 \mu \mathrm{M}$ & $17.8 \mu \mathrm{M}$ & $14.8 \mu \mathrm{M}$ & $16.6 \mu \mathrm{M}$ \\
$35.2 \mu \mathrm{M}$ & $32.4 \mu \mathrm{M}$ & $33.2 \mu \mathrm{M}$ & $36.3 \mu \mathrm{M}$ & $40.9 \mu \mathrm{M}$ & $33.1 \mu \mathrm{M}$ \\
$70.4 \mu \mathrm{M}$ & $45.8 \mu \mathrm{M}$ & $68.6 \mu \mathrm{M}$ & $46.7 \mu \mathrm{M}$ & $73.2 \mu \mathrm{M}$ & $66.2 \mu \mathrm{M}$
\end{tabular}

Table S2. Calculation of the \%P in a commercial fertilizer sample based on the data from varied dilutions of this fertilizer as presented in Table S1.

\begin{tabular}{|c|c|c|c|c|c|c|c|c|c|c|c|c|}
\hline \multirow{3}{*}{$\begin{array}{c}\text { Input } \\
\text { Phosphorus }\end{array}$} & \multicolumn{6}{|c|}{ Centrifuge Tube Assay } & \multicolumn{6}{|c|}{ Microtiter Plate Assay } \\
\hline & \multicolumn{3}{|c|}{ Linear } & \multicolumn{3}{|c|}{ Fractional Saturation } & \multicolumn{3}{|c|}{ Linear } & \multicolumn{3}{|c|}{ Fractional Saturation } \\
\hline & Average & $\begin{array}{l}\text { Lower } \\
\text { Bound }\end{array}$ & $\begin{array}{l}\text { Upper } \\
\text { Bound }\end{array}$ & Average & $\begin{array}{l}\text { Lower } \\
\text { Bound }\end{array}$ & $\begin{array}{l}\text { Upper } \\
\text { Bound }\end{array}$ & Average & $\begin{array}{l}\text { Lower } \\
\text { Bound }\end{array}$ & $\begin{array}{l}\text { Upper } \\
\text { Bound }\end{array}$ & Average & $\begin{array}{l}\text { Lower } \\
\text { Bound }\end{array}$ & $\begin{array}{l}\text { Upper } \\
\text { Bound }\end{array}$ \\
\hline $4.4 \mu \mathrm{M}$ & $5.6 \%$ & $-0.2 \%$ & $12.7 \%$ & $9.0 \%$ & $3.9 \%$ & $11.9 \%$ & $6.1 \%$ & $-0.3 \%$ & $13.3 \%$ & $9.7 \%$ & $4.0 \%$ & $12.4 \%$ \\
\hline $8.8 \mu \mathrm{M}$ & $8.1 \%$ & $4.7 \%$ & $12.3 \%$ & $7.6 \%$ & $3.3 \%$ & $10.0 \%$ & $8.7 \%$ & $5.3 \%$ & $13.0 \%$ & $8.5 \%$ & $3.5 \%$ & $10.5 \%$ \\
\hline $17.6 \mu \mathrm{M}$ & $9.1 \%$ & $6.9 \%$ & $11.7 \%$ & $7.5 \%$ & $3.5 \%$ & $9.4 \%$ & $9.7 \%$ & $7.4 \%$ & $12.5 \%$ & $8.5 \%$ & $3.8 \%$ & $10.1 \%$ \\
\hline $35.2 \mu \mathrm{M}$ & $9.3 \%$ & $7.7 \%$ & $11.3 \%$ & $9.6 \%$ & $5.8 \%$ & $10.8 \%$ & $9.9 \%$ & $8.3 \%$ & $11.9 \%$ & $11.8 \%$ & $6.8 \%$ & $11.9 \%$ \\
\hline $70.4 \mu \mathrm{M}^{*}$ & $6.6 \%$ & $5.6 \%$ & $7.8 \%$ & $9.8 \%$ & $9.5 \%$ & $11.9 \%$ & $6.4 \%$ & $5.4 \%$ & $7.58 \%$ & $10.5 \%$ & $9.1 \%$ & $9.6 \%$ \\
\hline Average & $8.0 \%$ & $4.8 \%$ & $12 \%$ & $8.7 \%$ & $5.2 \%$ & $10.8 \%$ & $8.6 \%$ & $5.2 \%$ & $12.7 \%$ & $9.8 \%$ & $5.4 \%$ & $10.9 \%$ \\
\hline
\end{tabular}

Table S1 and S2 notes: To calculate these values, we determined the $P$ from each dilution of fertilizer using the standard curve (see Figure 2 \& Table S1), and back calculated the dilution ratios to determine the $\% \mathrm{P}$ in the starting material. Based on the manufacturer's label, which listed $23 \% \mathrm{P}\left(\right.$ as $\left.\mathrm{P}_{2} \mathrm{O}_{5}\right)$, we expected $10.1 \%$ elemental $P$, while the TP value as reported by Brookside Labs was $9.54 \% \mathrm{P}$. The lower and upper bounds are $95 \%$ confidence intervals based on the lower and upper bounds of the standard curves (see calculations section in Methods).

${ }^{*}$ The $70.4 \mu \mathrm{M}$ input $\mathrm{P}$ measurements taken using the linear fits were not included in the average percentages for those fits because $70.4 \mu \mathrm{M}$ is outisde of the linear range. 
A

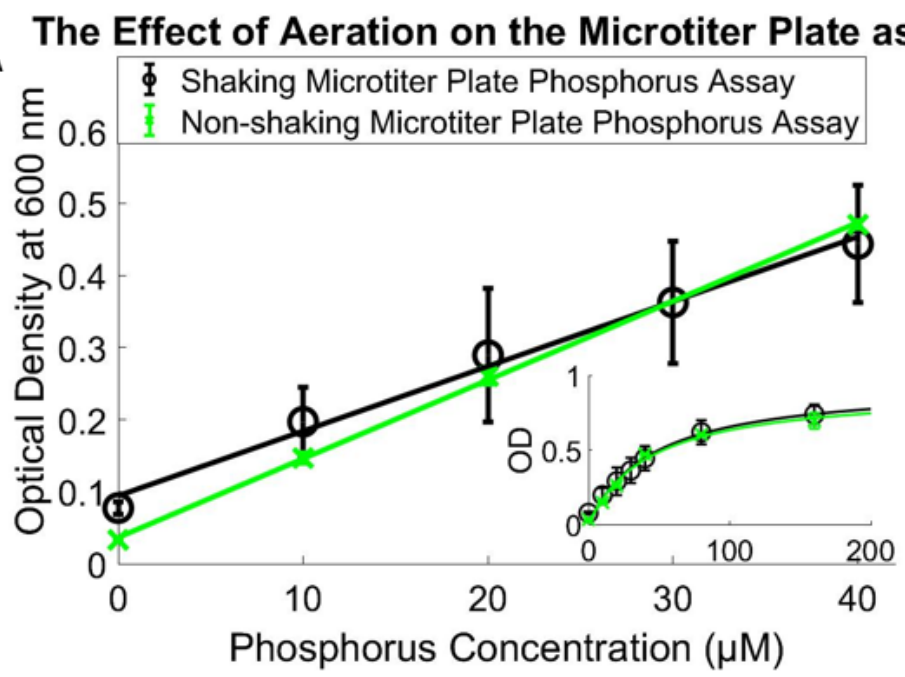

B

\section{6- well Microtiter Plate}

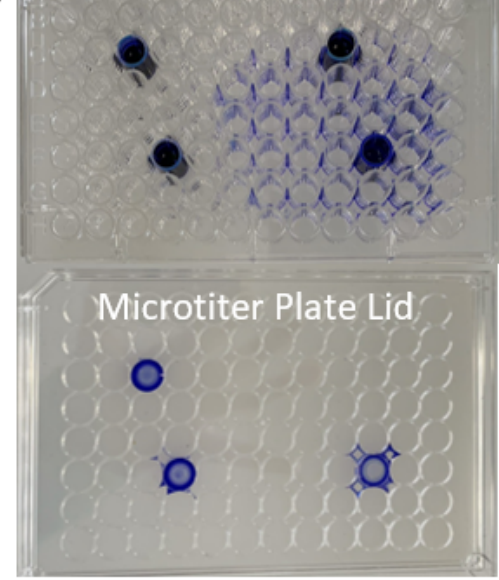

Figure S1. The effect of aeration on the microtiter plate assay. (A) Aerating the yeast cultures during the growth period did not alter the relationship between input $P$ and optical density, but it did result in a small increase in variability. The standard curve for the static (non-shaking) microtiter plate assay (green) is the same as referenced in Figure 2. The standard curve for the shaking microtiter plate assay (black) represents the average +/-SD of 3 independent experiments with 12 technical replicates each. Aeration was introduced by shaking the plates continuously at $850 \mathrm{rpm}$ (chosen as the minimum value necessary to prevent settling in the plates) using a Southwest Science plate shaker (Cat\# SBT1500-H; 2 mm diameter orbit) over a 4-day incubation period at $30^{\circ} \mathrm{C}$. These data show that under either condition, yeast growth is linear between 0-40 $\mu \mathrm{M}$ phosphorus (main figure, fitted to $\mathrm{y}=\mathrm{mx}+\mathrm{b}$ ) and saturates as $\mathrm{P}$ increases (inset, fitted to the fractional saturation function, see Methods). (B) To investigate the reason for the increased variability in the aerated plates, we added $200 \mu \mathrm{L}$ (the same volume used for the yeast assay) of blue dye to 4 wells on a single plate, shaking at $850 \mathrm{rpm}$ for 1 hour. As seen here, the blue dye is able to accumulate on the lid of the plate and travel between wells. This observation suggests that the increased variability in the aerated plates results from cross contamination. These data, together with the desire to avoid unnecessary equipment lead us to suggest performing these assays as static cultures, a conclusion reached by other labs as well (see e.g., Hung et al., 2018) 


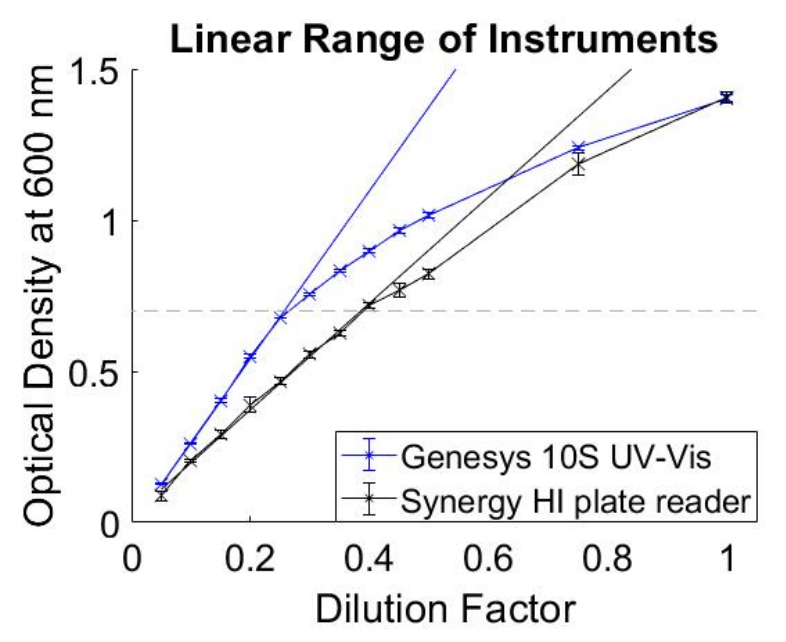

Figure S2. A single yeast culture was diluted to test the linear range of each instrument. The yeast culture was diluted as indicated, and the OD600 was recorded on the specified instrument. These data show that both the UV-Vis and the Synergy HI plate reader loose linearity near $O D=0.7$, indicated by the gray dotted line. $n=3$ or 6 for the centrifuge tube and microtiter plate samples respectively; error bars provide the standard deviation; some are obscured by the symbols. 


\section{Supplementary Methods}

\subsection{Sources of Chemicals and Materials}

\section{Media Components:}

Phosphorus-Free Media Base components: Sodium chloride (Cat\# vw6430-7) and glucose (Cat\# 0188) were purchased from VWR International. Potassium chloride (Cat\# P217) was purchased from Fisher Scientific (Waltham, MA). Calcium chloride (Cat\# 223506), magnesium chloride (Cat\# 8.14733.0100), ammonium sulfate (Cat\# A7523) were obtained from Sigma Aldrich (St. Louis, MO).

Vitamins: Inositol (Cat\# A13586), riboflavin (Cat\# A11764), and thiamine hydrochloride (Cat\# A19560) were purchased from Alfa Aesar (Haverhill, MA). Biotin (Cat\# B4501), calcium pantothenate (Cat \#CS731), folic acid (Cat\# F7876), niacin (Cat \#N0761), paminobenzoic acid (Cat \#100536), and pyridoxine hydrochloride (Cat \#P6280) were obtained from Sigma Aldrich.

Metals: Boric acid (Cat\# BP168-1), potassium iodide (Cat\# P410), and magnesium sulfate (Cat\# M65) were purchased from Fisher Scientific. Copper sulfate (Cat\# 209198), ferric chloride (Cat\# 236489), and sodium molybdate (Cat\# M1003) were purchased from Sigma Aldrich.

Antibiotics: Ampicillin (Cat\# AAJ60977-06) was purchased from VWR. Kanamycin sulfate (Cat\# BP906-5) was purchased from Fischer Scientific.

Buffers: Sodium citrate (Cat\# S279) was purchased from Fischer Scientific. Citric acid (Cat\# 0529) was purchased from VWR International (Radnor, PA).

SRP Components: Ammonium molybdate tetrahydrate (Cat\# M1019) and stannous chloride (Cat\# 208256) were purchased from Sigma Aldrich.

\section{Materials:}

Centrifuge tubes (Cat\# 21008-951) and disposable cuvettes (Cat\# 97000-586) were purchased from VWR International. Costar 3596 (Cat\# EF5353F-CS), 96-well clear flatbottom plates were purchased from Daigger Scientific (Buffalo Grove, IL). 


\subsection{Preparation of Growth Media}

Note: If members of the community would like to try our assay but are inhibited by difficulties acquiring or mixing these materials, we can provide aliquots of the metals and vitamins as well as samples of media.

Preparation of Phosphorus-Free Synthetic Defined Media (PoSD) (1X) (Saldanha et al., 2004).

The media was typically prepared to a $2 \mathrm{X}$ stock and diluted to $1 \mathrm{X}$ media by sample water. To prepare the $2 X$ stock please double all ingredients below (see Table 1 ).

Fill a $1 \mathrm{~L}$ graduated cylinder to $500 \mathrm{ml}$ with double deionized water $\left(\mathrm{ddH}_{2} \mathrm{O}\right)$, add $0.1 \mathrm{~g}$ calcium chloride, $0.1 \mathrm{~g}$ sodium chloride, $0.5 \mathrm{~g}$ magnesium chloride, $0.1 \mathrm{~g}$ potassium chloride and $5 \mathrm{~g}$ ammonium sulfate. Fill to $1 \mathrm{~L}$ with $\mathrm{ddH}_{2} \mathrm{O}$. Aliquot $500 \mathrm{~mL}$ into $2-1 \mathrm{~L}$ borosilicate glass bottles. Autoclave for 15 minutes at $15 \mathrm{psi}, 121^{\circ} \mathrm{C}$. Store at room temperature in the dark.

\section{Preparation of Glucose}

A stock solution of $20 \%$ glucose is made by dissolving $10 \mathrm{~g}$ of glucose powder in $50 \mathrm{ml}$ of deionized water, add start stir bar before adding liquid; stir powder in slowly to avoid clumps. Filter sterilize the solution using a $0.22 \mu \mathrm{m}$ filter, and store at room temperature in the dark. When ready to use media, add $25 \mathrm{ml}$ of $20 \%$ glucose to $500 \mathrm{ml}$ media for a final concentration of $0.95 \%$ glucose; normally [glucose] is $2 \%$ in synthetic defined media, but we are following Saldanha et al., 2004.

\section{Preparation of Metals}

Metals were made to $1000 \mathrm{X}$ concentration:

Fill a $500 \mathrm{~mL}$ graduated cylinder to $250 \mathrm{ml}$ with $\mathrm{dd}_{2} \mathrm{O}$, add $500 \mathrm{mg}$ boric acid, $40 \mathrm{mg}$ copper sulfate, $100 \mathrm{mg}$ potassium iodide, $200 \mathrm{mg}$ ferric chloride, $400 \mathrm{mg}$ magnesium sulfate, and $200 \mathrm{mg}$ sodium molybdate. Fill to $500 \mathrm{~mL}$ with $\mathrm{ddH}_{2} \mathrm{O}$. Transfer to a $1 \mathrm{~L}$ borosilicate glass bottle. Autoclave for 15 minutes at $15 \mathrm{psi}, 121^{\circ} \mathrm{C}$. Store at room temperature in the dark.

\section{Preparation of Vitamins}

Vitamins were made to $1000 \mathrm{X}$ concentration:

Fill a $500 \mathrm{~mL}$ graduated cylinder to $250 \mathrm{ml}$ with $\mathrm{ddH}_{2} \mathrm{O}$, add $1 \mathrm{mg}$ biotin, $200 \mathrm{mg}$ calcium pantothenate, $1 \mathrm{mg}$ folic acid, $1000 \mathrm{mg}$ Inositol, $200 \mathrm{mg}$ Niacin, $100 \mathrm{mg}$ P-aminobenzoic acid, $200 \mathrm{mg}$ pyridoxine hydrochloride, $100 \mathrm{mg}$ riboflavin, and $200 \mathrm{mg}$ thiamine hydrochloride. Fill to $500 \mathrm{~mL}$ with $\mathrm{ddH}_{2} \mathrm{O}$. Transfer to a $1 \mathrm{~L}$ borosilicate glass bottle. Autoclave for 15 minutes at $15 \mathrm{psi}, 121^{\circ} \mathrm{C}$. Store at room temperature in the dark. 
Once the above solutions are prepared practice sterile technique during use by using only sterile pipettes to transfer media, flaming the mouth of the bottles before and after pouring liquid and working around a flame.

Preparation of Assay-Ready Media - typically made $50 \mathrm{ml}$ at a time, but can be adjusted for the number of samples being tested.

Combine $100 \mu \mathrm{l} 1000 x$ vitamins and metals, $100 \mu \mathrm{l}$ 1000x ampicillin and kanamycin, 1 $\mathrm{ml} 1 \mathrm{M}$ sodium citrate, $1 \mathrm{ml} 1 \mathrm{M}$ citric acid, and $5 \mathrm{ml} 20 \%$ glucose in a $50 \mathrm{ml}$ graduated cylinder. Fill to $50 \mathrm{ml}$ with the $2 \mathrm{X}$ phosphorus-free base media described above. Note these proportions will be appropriately diluted to $1 \mathrm{x}$ by addition of samples or calibration water in the assay.

\section{Preparation of Phosphorus-Limited Media}

To bring phosphate levels up for growing stock cultures, phosphate-limited media was made by adding glucose, vitamins, and minerals to the diluted $1 \mathrm{X}$ phosphorus-free base media as described above, and then supplementing with freshly diluted potassium phosphate to a final concentration of $50 \mu \mathrm{M}$. Preparation of samples for standard curves is performed in a similar way. Note that any dilutions of $1 \mathrm{M}$ potassium phosphate should be made fresh each day.

\subsection{Preparation of Phosphorus-Depleted yeast cultures}

Inoculate $50 \mathrm{ml}$ of $1 \mathrm{X}$ phosphorus-limited SD media with a single colony taken from a typical YPD plate and incubate for four days at $30^{\circ} \mathrm{C}$, at which time the yeast have reached the stationary phase. Allowing the yeast to reach stationary phase depletes their internal $\mathrm{P}$ storage so that their only $\mathrm{P}$ source will be from the sample or standard used in the assay. 


\subsection{Cost Analysis}

Microtiter plate assay

- $\$ 20 / \mathrm{hr}$. technician time; $\sim 1.5$ hours to complete a plate

- $\$ 5.68$ per microtiter plate

- $\quad$ \$2 in assay-ready media

- Total: $\$ 37.68$ per full plate of 60 usable wells ( 6 standard curve wells and 18 sample tests, each paired with two controls; 54 wells assumes outer 36 wells are left empty to avoid edge-related artifacts)

- \$2.10 per sample. The cost could potentially be further reduced if more samples were run per plate, e.g., by using the outer wells of the plate. Another possibility would be to leave out the positive controls where known $[\mathrm{P}]$ is added to the sample to control for the presence of possible growth inhibitors. However, unless users are confident in the absence of any possible inhibitors, we do not advise this.

\section{Centrifuge tube assay}

- $\$ 20 / h r$. technician time; $\sim 2$ hours to complete a standard set as done in our lab (24 tubes, corresponding to 6 standard curve tubes, plus six samples, each paired with two control tubes)

- $\$ 0.81$ per tube $=\$ 19.39$

- $\quad \$ 12.50$ in assay-ready media for a set of 24 tubes

- Total: $\$ 71.89$ for a set of 24 tubes, with six samples

- \$11.98 per sample. As above, the cost could potentially be reduced if more samples were run per set, e.g., by leaving out the positive controls where known [P] is added to the sample to control for the presence of possible growth inhibitors. However, unless users are confident in the absence of any possible inhibitors, we do not advise this.

\subsection{General Notes to be considered before performing either assay:}

- Practice good pipetting, no bubbles.

- The presence of bubbles in pipetting alters the true volume being added; this can result in incorrect proportions of media and samples and cause aberrant results.

- Dispose of tips after each use to avoid cross-contamination.

- If using a multichannel pipette with the microtiter plate, make sure each tip is secured and that they all intake the same volume of solution.

- Always agitate yeast mixture before aliquoting to different tubes or wells.

- Yeast settle quickly. Proper mixing will ensure the amount of yeast delivered to each assay is the same. Failure to mix can result in aberrant results.

- Media should be stored in glassware that has been washed using phosphate-free soap and acid rinsed 3 times using $0.5 \mathrm{M} \mathrm{HCl}$ to remove any residual phosphorus.

- Contamination (e.g., from P-containing soap or remnant media) can cause considerable interference in measurements, Thus, we recommend that plastic materials be used one time only to prevent cross-contamination and residual phosphorus carry-over between experiments. If users do attempt to reuse plastic, it is essential that it be washed thoroughly.

- Laboratory yeast cultures can be poured down the drain after being sterilized by addition of bleach or alternatively by autoclaving. 


\subsection{Centrifuge Tube Assay}

Equipment needed:

- Visible light spectrometer

- $1000 \mu$ l pipetteman

- 100 or $200 \mu$ l pipetteman

- Serological pipette bulb

Supplies needed:

- 3 centrifuge tubes $(50 \mathrm{ml}$ ) for each sample (one for the sample and two for samplespecific controls) being tested (note: $15 \mathrm{ml}$ centrifuge tubes will not work as they do not provide enough room for respiration)

- $1.5 \mathrm{ml}$ plastic cuvettes for reading optical density

- $5 \mathrm{ml}$ serological pipettes

- $50 \mathrm{ml}$ serological pipettes

- $1000 \mu$ l pipette tips

- 100 or $200 \mu$ l pipette tips

\section{Control Samples}

1. Phosphorus-free media without yeast but with test water (or diluted to $1 \mathrm{X}$ with $\mathrm{ddH}_{2} \mathrm{O}^{1}$ for standard curves)

a. This control (one for each sample) is used as a background blank, the value of which is subtracted from the OD reading for that sample. It is assembled immediately before plate reading to avoid the possible effects of microbial growth in the sample.

2. Media with yeast and $5 \mathrm{mls}$ of $\mathrm{ddH}_{2} \mathrm{O}$ containing $20 \mu \mathrm{M} \mathrm{P}$ (diluted from freshly made $1 \mathrm{mM}$ potassium phosphate)

a. Comparison of this control (one for each sample) to the standard curve sample with $20 \mu \mathrm{M} P$ will enable the user to determine whether possible growth inhibitors are present in the test sample.

\footnotetext{
${ }^{11}$ We use double-deioinzed water, but double-distilled or any suitable lab water should work
} 
3. Media with yeast and no phosphorus or test water (media diluted by $\mathrm{ddH}_{2} \mathrm{O}$ instead of test water)

a. This control (one per set of tubes) will indicate the presence of phosphorus contamination in media or glassware. If the yeast remained at the starting OD, no contamination was observed. Note that this tube will also serve as the zero $\mathrm{P}$ point for the standard curve.

\section{Assay Samples}

1. Prepare $5 \mathrm{ml}$ of assay-ready media for each tube being used, but do not distribute it yet.

a. To perform a set of 24 tubes (6 standards, and 6 samples, with two sample-specific controls each) would require $120 \mathrm{ml}$ of assay-ready media total. However only $90 \mathrm{ml}$ of media (18 tubes worth) are needed to start the assay, since the negative controls (sample blanks) will be made the day of the final reading to avoid possible interference by bacterial growth.

2. Add phosphorus-depleted yeast to the prepared assay-ready media; use an amount sufficient to achieve a final optical density of 0.05 at $600 \mathrm{~nm}$.

a. For the 24 tubes described above, 18 require yeast (the blanks do not). Thus, for a starting yeast concentration of 0.650 , you would add $6.92 \mathrm{ml}$ of yeast to the $90 \mathrm{ml}$ of assay-ready media.

3. Prepare $5 \mathrm{ml}$ of each $\mathrm{P}$ calibration standard in $\mathrm{ddH}_{2} \mathrm{O}$.

a. A typical standard curve would include $5 \mu \mathrm{M}, 10 \mu \mathrm{M}, 20 \mu \mathrm{M}, 40 \mu \mathrm{M}$, and $80 \mu \mathrm{M}$ P. Note that after this $5 \mathrm{ml}$ is mixed with media, the final $[\mathrm{P}]$ will be halved, but because the samples will be similarly diluted, this does not cause problems.

b. P should be diluted from $1 \mathrm{mM}$ potassium phosphate freshly made that day from $1 \mathrm{M}$ potassium phosphate.

4. Aliquot $5 \mathrm{ml}$ of yeast and media into each $50 \mathrm{ml}$ centrifuge tube (except those being saved for the sample blanks)

5. Add $5 \mathrm{ml}$ of control water, calibration standard or water sample to each tube containing media and yeast.

6. Incubate at $37^{\circ} \mathrm{C}$ without shaking for 4 days.

a. Though lack of shaking and $37^{\circ}$ are unusual for yeast, we designed the assay to be done at $37^{\circ}$ and without shaking to minimize equipment needs. 
$b$. We do not recommend shortening the time of incubation because the yeast may need time to extract $P$ from complex substrates.

After 4 days of incubation:

7. For each sample, prepare a blank by filling a tube with $5 \mathrm{ml}$ of assay-ready media and $5 \mathrm{ml}$ of sample (plus one with $\mathrm{dd}_{2} \mathrm{O}$ ). This should be done immediately before the optical density is taken.

8. Read optical density of all tubes at $600 \mathrm{~nm}$.

a. Blank each sample using the mixture of freshly diluted assay-ready media and the test water mentioned above.

b. Mix each sample immediately before reading to prevent yeast settling. 


\subsection{Microtiter Plate Assay}

Equipment needed:

- Plate reader with $600 \mathrm{~nm}$ filter

- $1000 \mu$ pipetteman

- 100 or $200 \mu \mathrm{l}$ pipetteman

- Serological pipette bulb

Supplies needed:

- 1 - 96 well flat bottom plate per 18 samples ( $200 \mu$ l wells)

- $5 \mathrm{ml}$ serological pipettes

- $50 \mathrm{ml}$ serological pipettes

- $1000 \mu$ pipette tips

- 100 or $200 \mu$ pipette tips

\section{Control Samples}

1. Phosphorus-free media (diluted to $1 \mathrm{X}$ by test water or $\mathrm{ddH}_{2} \mathrm{O}$ for standard curves)

a. This control (one for each sample) is used as a background blank, the value of which is subtracted from the OD reading for that sample. It is assembled immediately before plate reading to avoid the possible effects of microbial growth in samples.

2. Media with yeast and $100 \mu \mathrm{ldd} \mathrm{H}_{2} \mathrm{O}$ containing $20 \mu \mathrm{M} \mathrm{P}$ (diluted from freshly made $1 \mathrm{mM}$ potassium phosphate)

a. Comparison of this control (one for each sample) to the standard curve sample with $20 \mu \mathrm{M}$ P will enable the user to determine whether possible growth inhibitors are present in the test sample.

3. Media with yeast and no phosphorus or test water (media diluted by $\mathrm{ddH}_{2} \mathrm{O}$ instead of test water)

a. This control (one per plate) will indicate the presence of phosphorus contamination in media or glassware. If the yeast remained at the starting OD, no contamination was observed. Note that this well will also serve as the zero $\mathrm{P}$ point for the standard curve. 
4. $\mathrm{ddH}_{2} \mathrm{O}$ containing $100 \mu \mathrm{M}$ ampicillin and kanamycin is used to fill the outer wells.

a. This controls for potential edge-related artifacts during absorbance measurements. We did not use the exterior of the plate. Instead, we filled outer wells with $200 \mu \mathrm{l}$ of the double deionized water containing $100 \mu \mathrm{M}$ ampicillin and kanamycin (the antibiotics may not be necessary but are added to maintain consistency across the plate).

Assay Samples:

1. Prepare $100 \mu \mathrm{l}$ of assay-ready media for each well being used, but do not distribute it yet.

a. To perform a full plate (6 standards, and 18 samples (with two samplespecific controls each)), would require $6.0 \mathrm{ml}$ of assay-ready media total. However only $4.2 \mathrm{ml}$ of media is needed to start the assay, as the negative controls (sample blanks) will be made the day of the final reading to avoid possible interference by bacterial growth.

2. Add phosphorus-depleted yeast to the prepared assay-ready media; use an amount sufficient to achieve a final optical density of 0.05 at $600 \mathrm{~nm}$.

a. For the plate described above, 42 wells require yeast (the blanks do not). Thus, for a starting yeast concentration of 0.650 , you would add $323 \mu \mathrm{l}$ of yeast to the $4.2 \mathrm{ml}$ of assay-ready media.

3. Prepare $100 \mu \mathrm{l}$ of each $\mathrm{P}$ calibration standard in $\mathrm{dd}_{2} \mathrm{O}$.

a. A typical standard curve would include $5 \mu \mathrm{M}, 10 \mu \mathrm{M}, 20 \mu \mathrm{M}, 40 \mu \mathrm{M}$, and $80 \mu \mathrm{M}$ P. Note that after this $100 \mu \mathrm{l}$ is mixed with media, the final [P] will be halved, but because the samples will be similarly diluted, this does not cause problems.

b. P should be diluted from $1 \mathrm{mM}$ potassium phosphate freshly made that day from $1 \mathrm{M}$ potassium phosphate.

i. We suggest making no less than $50 \mathrm{ml} 1 \mathrm{mM} \mathrm{P}$ to avoid errors in the standards related to pipetting smaller amounts for this dilution.

4. Aliquot $100 \mu \mathrm{l}$ of yeast and media into microtiter plate wells (except those being saved for the sample blanks).

5. Add $100 \mu \mathrm{l}$ of control water, calibration standard or water sample to each well containing media and yeast.

6. Add $200 \mu \mathrm{l}$ of $\mathrm{ddH}_{2} \mathrm{O}$ containing $100 \mu \mathrm{M}$ antibiotics to outer wells.

7. Incubate at $30^{\circ} \mathrm{C}$ without shaking for 4 days. 
8. For each sample, prepare a blank by filling a well with $100 \mu$ of assay-ready media and $100 \mu \mathrm{l}$ sample (plus one with $\mathrm{dd}_{2} \mathrm{O}$ ). This should be done immediately before the optical density is taken.

9. Read optical density of the plate at $600 \mathrm{~nm}$.

a. Blank each sample using the mixture of freshly diluted assay-ready media and the test water mentioned above.

b. Mix each sample immediately before reading to prevent yeast settling. 


\section{Supplement References}

Hung, C.-W.; Martínez-Márquez, J. Y.; Javed, F. T.; Duncan, M. C. A Simple and Inexpensive Quantitative Technique for Determining Chemical Sensitivity in Saccharomyces Cerevisiae. Sci. Rep. 2018, 8 (1), 11919. https://doi.org/10.1038/s41598-018-30305-z.

Saldanha, A.J., Brauer, M.J., Botstein, D., 2004. Nutritional Homeostasis in Batch and Steady-State Culture of Yeast. MBoC 15, 4089-4104. https://doi.org/10.1091/mbc.e04$\underline{04-0306}$ 